\title{
Considerations on clinical trials of leprosy treatment: need of novel drug combinations
}

Clin. Invest. (2013) 3(7), 617-635

Considering that after 30 years of using multidrug therapy (MDT), leprosy eradication has still not been achieved, leprosy treatment must remain on the drug discovery agenda. Due to the complexities inherent in leprosy disease and the many methodological issues involved in clinical trials, the task of translating the bench findings into clinical practice has been arduous. While the effectiveness of reducing the currently recommended MDT remains controversial, a number of highly bactericidal antibiotics and immune-modulatory drugs have emerged as prospective candidates to improve patient adherence and quality of life, reduce adverse effects and prevent resistance. To replace the standard WHO-MDT, the new combination must be the shortest, simplest and, consequently, most affordable treatment possible.

Keywords: clinical trial • drug combination • leprosy $•$ multidrug therapy $•$ relapse

- resistance $\cdot$ surrogate end point $\cdot$ treatment

Leprosy is an infectious disease caused by Mycobacterium leprae, a slow-growing bacteria that infects Schwann cells and macrophages. This tropical disease, now considered neglected, is still present in more than 130 countries worldwide. Although its prevalence has been reduced over the past years, the detection rate of cases with permanent disabilities has remained stable at around 0.25/100,000 inhabitants [1].

$M$. leprae was one of the first agents linked to an infectious disease in the 19th century but the effective antibiotic, intravenous sulphone, only appeared in 1943 [2]. Soon afterwards, a new oral derivate called dapsone (diamino-diphenylsulphone [DDS]) became the standard chemotherapy treatment. Until 1982, sulfone monotherapy was the only validated treatment regimen for leprosy [3]. Upon the appearance of secondary DDS resistance in the 1970s, together with the ready availability of rifampin (RFM), a potent bactericidal drug, the use of combined regimens was recommended [4]. Several treatment combinations, mainly based on previously proven effective tuberculosis therapy, were proposed to combine with DDS, such as RFM, thioamide drugs and isoniazid, which is not active against M. leprae. Combined therapy was implemented by several National Programs. For instance, in Paraguay and Malta, Isoprodian ${ }^{\circledR}(175 \mathrm{mg}$ of prothionamide, $50 \mathrm{mg}$ DDS and $175 \mathrm{mg}$ isoniazid) and RFM were extensively used with few reported relapse cases $[5,6]$. However, it was not until 1982 that the WHO Chemotherapy Study Group recommended the combined use of RFM and DDS with or without clofazimine (CLF) [7]. Implementation of this multidrug therapy (MDT), known as WHOMDT, began in most endemic countries. WHO-MDT is the current standard treatment and continues to be widely administered.

The introduction of MDT at fixed doses brought about important advances in the control of the disease [8]. The accompanying implementation strategies assured drug supply to all endemic countries in the form of specific free-of-cost blister packs
Ximena Illarramendi ${ }^{1}$, Maria Leide Wand del Rey de Oliveira², Anna Maria Sales ${ }^{1}$, José Augusto da Costa Nery $^{1}$ \& Euzenir Nunes Sarno*1

${ }^{1}$ Leprosy Laboratory, Oswaldo Cruz Institute, Fiocruz, Rio de Janeiro, RJ, Brazil

${ }^{2}$ Department of Dermatology, Federal University of Rio de Janeiro, RJ, Brazil

*Author for correspondence:

E-mail: euzenir@fiocruz.br

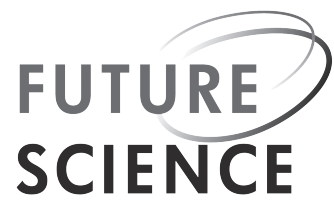

part of

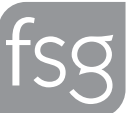


available for multibacillary (MB) and paucibacillary (PB) leprosy in separate presentations for children and adults. In addition, mobilization was encouraged to ensure that the infrastructure facilitating the delivery of healthcare services would be improved in the countries involved.

\section{Why is there a need to develop new treatment regimens for leprosy?}

Although the wide acceptance of WHO-MDT and the use of fixed-dose schemes have greatly contributed to important advances in leprosy treatment and the development of public health policies, their adverse effects have been considerable (see later section 'Principles of leprosy treatment'). In addition, current treatment is exceedingly long and reports of resistance against some of its component antibiotics are increasingly frequent. The general consensus is that new drugs are needed to develop a shorter, single treatment scheme [9-12]. A short scheme will certainly improve patient adherence and their quality of life. Increased compliance to treatments with new drug combinations may bring the additional benefit of reducing bacilli persistence and risk of resistance. However, a search for the terms 'leprosy' and 'treatment' in the WHO International Clinical Trials Registry Platform [201], containing data from the national clinical trial registries of several, often endemic, countries, showed no new studies. The few trials registered were all prior to 2009: a Phase III trial on the long-term use of CLF, the evaluation of the effect of body weight on drug concentrations and the effect of modified WHO-MDT schemes; suggesting a complete lack of initiatives and financing of research in the field.

\section{Principles of leprosy treatment \\ - Cure definition parameters}

In any clinical trial, the assessment methods used to measure patient responses to the treatment under investigation need to be very well defined and reliable [13]. However, in the case of leprosy many difficulties are encountered. The disease presents as a spectrum of clinical forms that develop according to the particular immunological response to the agent [14]. In addition, the long incubation period required by $M$. leprae equally demands a long period for bacterial clearance. The excellent adaptation to the host favors bacterial persistence in tissues even after completing regular treatment with standard WHO-MDT [15]. On occasions, there is no positive correlation between clinical and microbiological end points. Thus, defining objective and comparable parameters to evaluate the therapeutic effect in all patients is a cornerstone of clinical trials in leprosy.

The direct clinical benefits of leprosy treatment are hard to measure via assessment of the health condition of the patient based solely on observation and the interpretation of the disappearance or improvement of skin lesions and peripheral nerve involvement. Further complexity is added by the presence of reactions, such as immunoinflammatory events that may likely complicate the course of the disease and treatment. Reactions may manifest as inflamed skin patches or diffuse nodules with or without nerve tenderness and enlargement, or systemic manifestations, and may occur before, during, and after treatment [16]. Successive reactions may lead to the killing of bacteria by various mechanisms that lead to the production of cytokines and chemokines. During leprosy reactions, the development of an acute inflammatory process, which occurs parallel to the stimulation of cellular immunity induces the production of pro-inflammatory mediators such as interleukins, IFN $\gamma$ and TNF $\alpha$. This whole process contributes to the destruction of bacteria and exposure of large amounts of antigens [17], aided by the bactericidal activity of macrophages through the production of inducible nitric oxide synthase [18]. Furthermore, the use of steroids to control the reactions may affect the access of the antibiotics to the inflamed tissues in a way similar to the one affecting the entrance of antibiotics through the blood-brain barrier [19]. Corticosteroids, due to their anti-inflammatory action, inhibit the production of pro-inflammatory cytokines, consequently reducing bacterial destruction. However, no effect has been observed on bacterial clearance or killing by the use of concomitant steroids and MB WHO-MDT [20].

In the absence of a reliable clinical end point, the use of surrogate end points is recommended [21]. Bacterial index (BI) and morphological index (MI) have been used as biomarkers for MB leprosy [22,23]. Data from longitudinal cohort studies and clinical trials have shown that reductions in BI and MI result in direct clinical benefits to the patients in terms of reducing the frequency of reactions $[24,25]$ and, as such have been used to predict the effect of therapy.

Studies of mycobacterial metabolism are used as markers of bacterial viability and, therefore, of the bactericidal effects of drugs [26]. These in vitro assays are expensive and time-consuming, requiring large quantities of bacteria that can only be obtained after passage in the mouse foot-pad. The main drawback is that results are only obtained after a year has elapsed [27]. Other biomarkers such as the measurement of antiphenolic glycolipid-I antibody levels have been proposed as indicators for monitoring treatment since a decline is observed during and after treatment [28]. However, not all patients have antibodies, and discordant findings are frequent, especially among patients in reaction [29].

Which parameter can best reflect the effect of a therapeutic intervention in $\mathrm{PB}$ patients in whom these 
biomarkers cannot be used? Is the antibiotic effect best measured in these cases only by sign and symptom resolution? Since bacterial eradication from the tissues is extremely hard to measure, there is still a need to define a characteristic that can be objectively measured and evaluated as an indicator of the pharmacologic responses to an intervention in cases with no detectable acid-fast bacilli. New methods to determine the viability of Mycobacteria such as the real-time PCR, which permits the quantification of $M$. leprae RNA and DNA obtained from tissue samples and the detection of as few as 30 bacilli should preferably be used to measure therapeutic effect [30].

Overall, to date, no standardized, reproducible and consistent end point has been used to evaluate the meaning of a cure in leprosy. Thus, clinical, laboratory and genetic markers still require validation.

\section{- Drug combinations}

As in other bacterial diseases, drug combinations are recommended in leprosy to increase efficacy and reduce development of resistance and complications. Besides bactericidal drugs, treatments include weak bactericidal or bacteriostatic antibiotics with an additional antiinflammatory effect, due to the possible development of reactions during the course of the disease.

The duration, safety, efficacy, acceptability, simplicity and cost are all important elements to be taken into consideration in antibacterial treatments. Feasibility seems to have been considered key in deciding the makeup of the current schemes. The supervised monthly $600 \mathrm{mg}$ RFM and $300 \mathrm{mg}$ CLF doses with daily self-administered DDS and 50mg CLF is the standard recommended treatment for MB leprosy. The same scheme but without CLF is administered during a consecutive 6-month period to PB individuals [31]. Interestingly, CLF, a drug with a 70-day half-life, is given daily. RFM, the only bactericidal antibiotic with a 3-5 hour half-life, is administered in monthly doses. However, monthly RFM is recommended during adjunct corticosteroid therapy due to drug interaction between RFM and prednisone [32]. Furthermore, RFM is best absorbed after a period of fasting, whereas food increases absorption of CLF [33], although both drugs are given simultaneously in supervised doses.

Moreover, serious safety considerations need to be considered, specifically regarding DDS, which is the MDT component most often associated with adverse effects [34,35]. In general, side effects of WHO-MDT range from gastrointestinal distress to hemolytic anemia and the DDS hypersensitivity syndrome, which can be severe and even life-threatening [36,37]. The DDS hypersensitivity syndrome is a severe idiosyncratic reaction is now considered to be a drug-induced reaction with eosinophilia and systemic symptoms [38] and requires immediate discontinuation of treatment. Overall, the lethality rate of DDS hypersensitivity is $10 \%$, resulting in a condition of great concern [37].

\section{- Relapse}

Similar difficulties as to define established cure in leprosy are encountered when defining relapse criteria. Relapse is defined as the occurrence of new signs and symptoms of the disease in a patient who has successfully completed an adequate course of MDT [39]. The relapse rate has also been utilized as an outcome to assess the effectiveness of therapeutic regimens in leprosy.

Most relapse cases are explained by the persistence of live M. leprae in various tissues in MB leprosy and in the nerves in PB leprosy [40]; however, in hyperendemic areas, re-infection cannot be excluded. Haldar et al. found a 2.6 higher risk of relapse in patients living with active leprosy cases[41], while Rocha et al. observed that $31 \%$ of the 145 cases with relapse had had relatives who were diagnosed within the 5 -year period prior to relapse diagnosis [42].

Various researchers agree there is a subset of $\mathrm{MB}$ patients, particularly those at the lepromatous pole of the spectrum and those with a high bacterial burden, who are at substantial risk for relapse [42-45]. Other risk factors include inadequate therapy and immunosuppression [22,46-48].

While relapse in MB patients is relatively easy to clinically recognize by the presence of active skin lesions and an increased BI, in PB cases it is often difficult to distinguish relapse from reversal reaction. As a result, there are wide variations in relapse rate estimations after establishment of 'cure' criteria by the current WHOMDT policy [22]. These estimations range from zero in the 502 patients of the AMFES cohort in Ethiopia after a follow-up period of up to 8 years after completion of fixed-dose MDT [43], $1.84 \%$ in an 18-year follow-up period of 163 patients in India [49] to $2 \%$ in patients treated with up to 2 years of WHO-MDT [45,50]. Since most studies report less than $1 \%$, relapse in $\mathrm{MB}$ patients is considered to be very low as a result of nearly 30 years of the widespread use of MDT [39]. However, this is virtually a statement of 'absence of evidence', which by no means indicates 'evidence of absence' [51].

In many reports, relapse rates are contradictory and the long surveillance period needed for it to occur in MB leprosy is not always taken into account [52]. Most of these studies were held in reference centers with wellsupervised, highly regular MDT [47]. Good patient adherence favors treatment efficacy. However, in the field, defaulter rates and misclassifications of a single or a few skin lesions in $\mathrm{MB}$ and $\mathrm{PB}$ cases may occur [46]. In addition, insufficient treatment may be given 
when DDS is withdrawn after the occurrence of adverse effects, at which time CLF or RFM are then administered as monotherapy [53]. Consequently, operational problems may lead to higher relapse rates.

Since MDT does not destroy all the bacilli, the remaining bacteria will need to be killed and eliminated by an effective immune system, mainly by macrophages [54].The presence of active bacteria is the strongest stimulus to induce and maintain leprosy reactions. Thus, patients with a high bacterial burden, who are both at higher risk of relapse and of suffering recurrent reactions [55], would definitely benefit from a new generation of highly bactericidal MDT.

\section{- Resistance}

Emerging drug resistance has been observed against the RFM and DDS, basic components of the WHO-MDT regimen and the ofloxacin (OFL), which is one of the second-line bactericidal drugs [48,56,57]. Rapid DNAbased molecular assays have been developed to allow DDS-resistant strains (folP I gene) along with RFMresistant ( $r p o B$ gene) and quinolone-resistant ( $g y r A$ and gyrB) $M$. leprae strains to be detected [58]. The WHO project for Global Surveillance of Drug Resistance came at a most opportune time in 2008 in light of the wide disparity among countries and even among different regions within the same country regarding investigative approaches, management and collection of relapse data and patient samples [59]. At present, little information can be obtained from the vast majority of endemic countries, clearly indicative of relapse under reporting and weak monitoring capacity of the project [60].

\section{Clinical trials with standard WHO-MDT}

The initial MB treatment was given during a minimum 2-year period and until skin smears became negative. After proven efficacy was established by various reports (Table 1), the WHO Study Group on Chemotherapy of Leprosy suggested a standard 24-month WHO-MDT regimen $[4,8]$.

Although no clinical trials monitored relapse rates of the recommended regimens due to epidemiological and operational factors, further reduction in the duration of $\mathrm{MB}$ treatment was suggested [52]. The long duration of the MB leprosy treatment was neither viable nor affordable for most leprosy control programs thus, in 1998, the Seventh Expert Committee recommended reducing MB-MDT to 12 months [61]. Given the fact that the number of $\mathrm{MB}$ cases detected had reduced and that many of the patients were skin-smear negative at diagnosis, this decision was accepted [62].

Since current recommendations for MDT follow a fixed duration of treatment regardless of skin lesion characteristics or acid-fast bacilli eradication,
BI reduction has been used to compare the relative efficacy of treatment regimens of different duration. In Brazil, a strategic trial compared the WHO-MDT of fixed duration among $213 \mathrm{MB}$ patients. The mean BIs and reaction rates of the patients who received 12 doses $(\mathrm{n}=128)$ were similar to those treated with 24 doses $(n=85)$ of MDT [63]. This study and others were interpreted to indicate that the reduction to 12 doses did not compromise MDT effectiveness [45,64].

There is some evidence of the reduction of leprosy reactions with the use of WHO-MDT, although some studies are contradictory and incidence rates are very variable. A study in Brazil reported that 35 out of 70 patients had reactions while on WHO-MDT and 77\% of the 70 patients had reactions during treatment with 3 months of daily RFM-DDS followed by 21 months of $100 \mathrm{mg}$ daily DDS. The proportion difference was found to be statistically significant and this was considered to be due to the inclusion of CLF in WHOMDT [65]. However, even with the use of two drugs, with some anti-inflammatory effect reactions continue to complicate the course of the disease during and after completion of both PB and MB MDT schemes $[16,66]$.

To increase compliance and drug supply logistics a further reduction in number of doses and length of treatment, and uniform therapy for all patients was recommended by the WHO Technical Advisory Group at its third meeting [13]. The uniform-MDT regimen consists of 6 months of MB WHO-MDT for all new cases regardless of clinical form or bacterial status. A multicenter trial is in progress in India and China [67]. Other controlled trials have likewise been initiated in India [68] and Brazil [69] (Table 2). Preliminary results suggest that uniform MDT does not adequately treat patients with MB leprosy [10]; and PB patients suffer significantly more adverse effect related to hematological alterations than $\mathrm{PB}$ patients treated with WHO-MDT [70].

However, some countries, such as the USA do not follow WHO recommendations and have different guidelines. The US National Hansen's Disease Program recommends the use of daily rather than monthly RFM and for a longer period of time than WHO-MDT: 24 months for $\mathrm{MB}$ and 12 months for PB patients [71]. Several researchers also favor this scheme [22].

Revision of various trials developed to define the current WHO-MDT schemes (Tables 1 \& 2) reveals a considerable degree of heterogeneity and variability in effectiveness. The study samples are for the most part variable, have very different inclusion criteria, are too small in size and too stratified, all of which reduce the ability to identify outcome differences among the groups studied while making comparisons more difficult to interpret. The interventions, drug dosages and combinations, treatment durations and outcomes are 


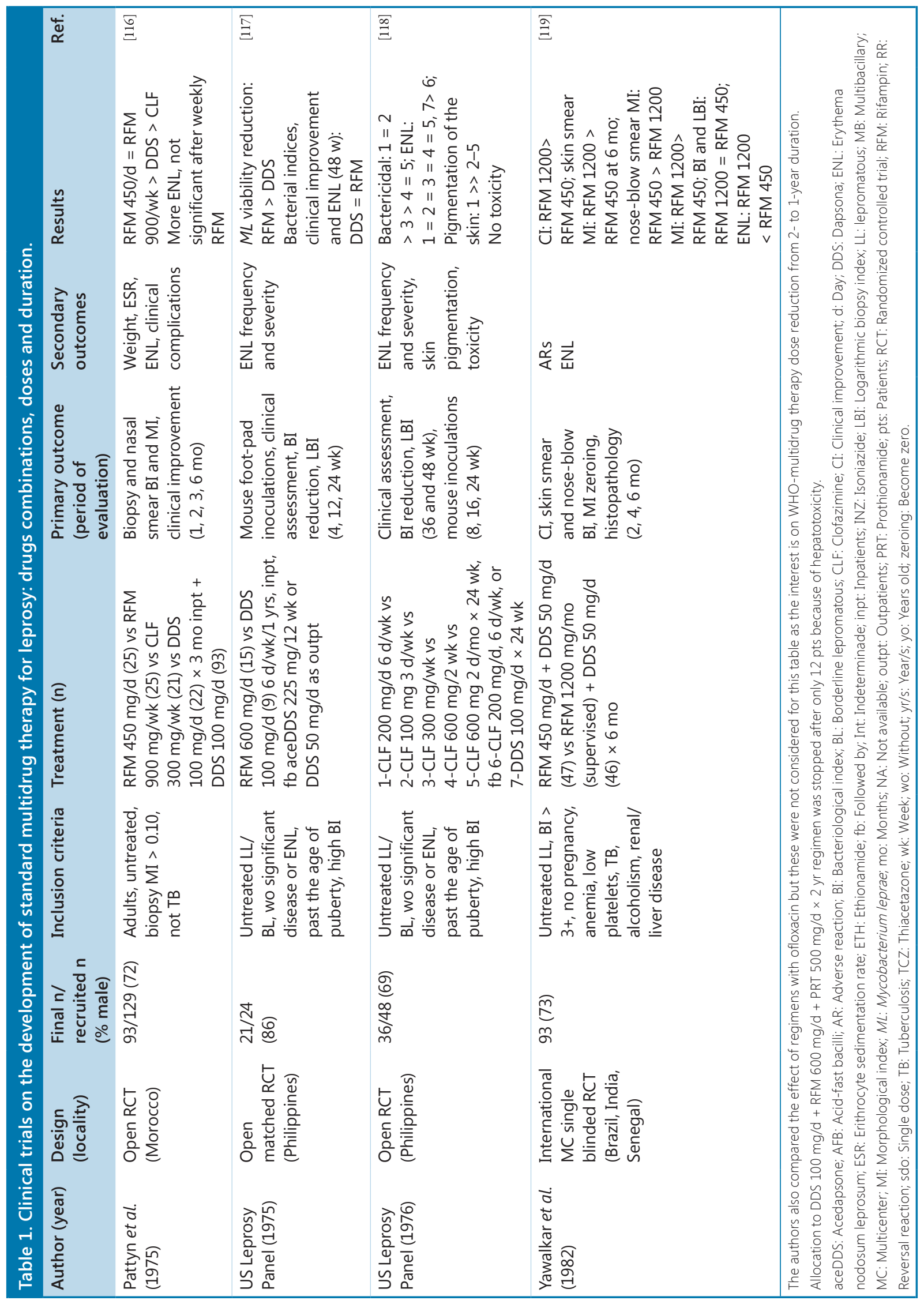




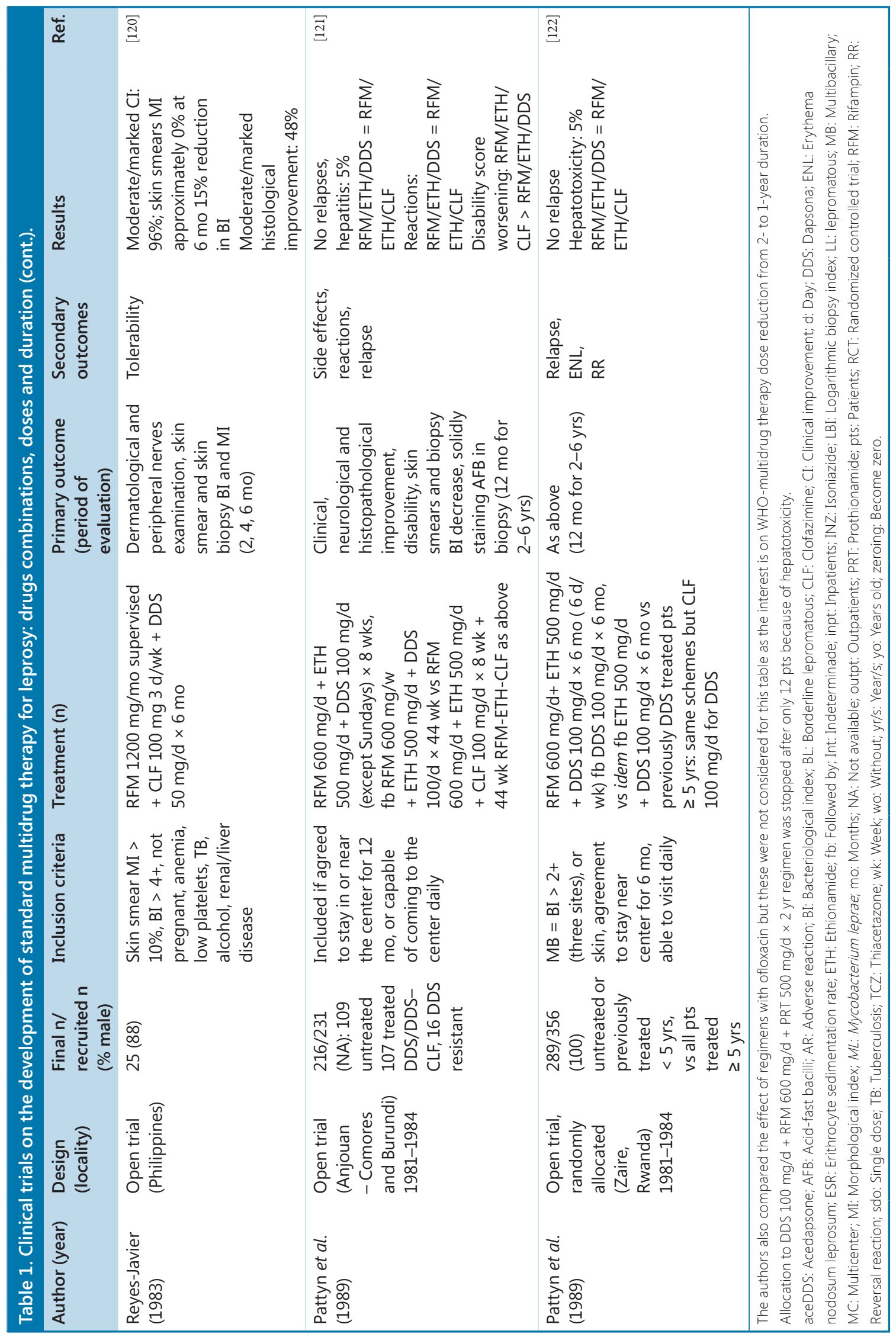




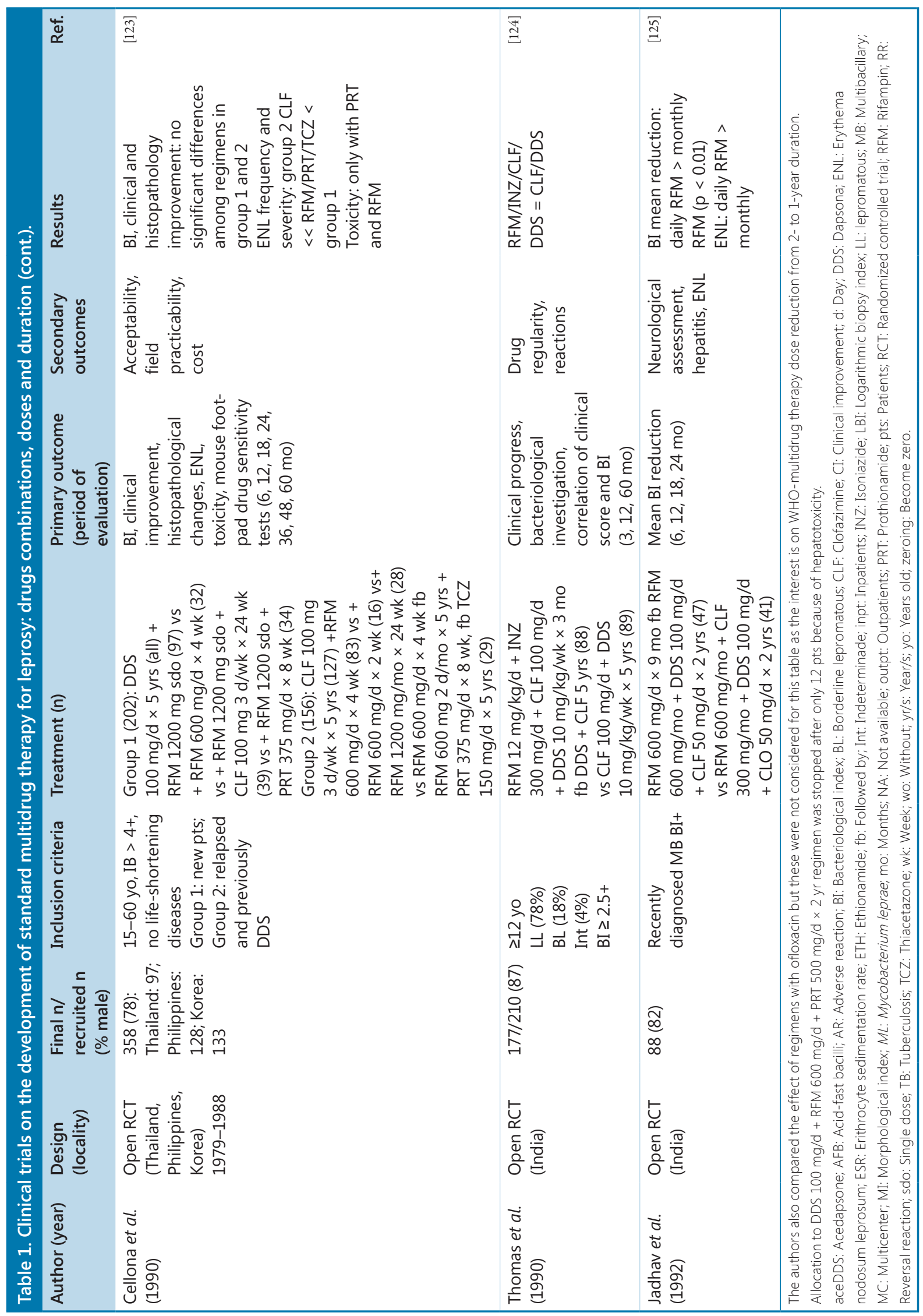




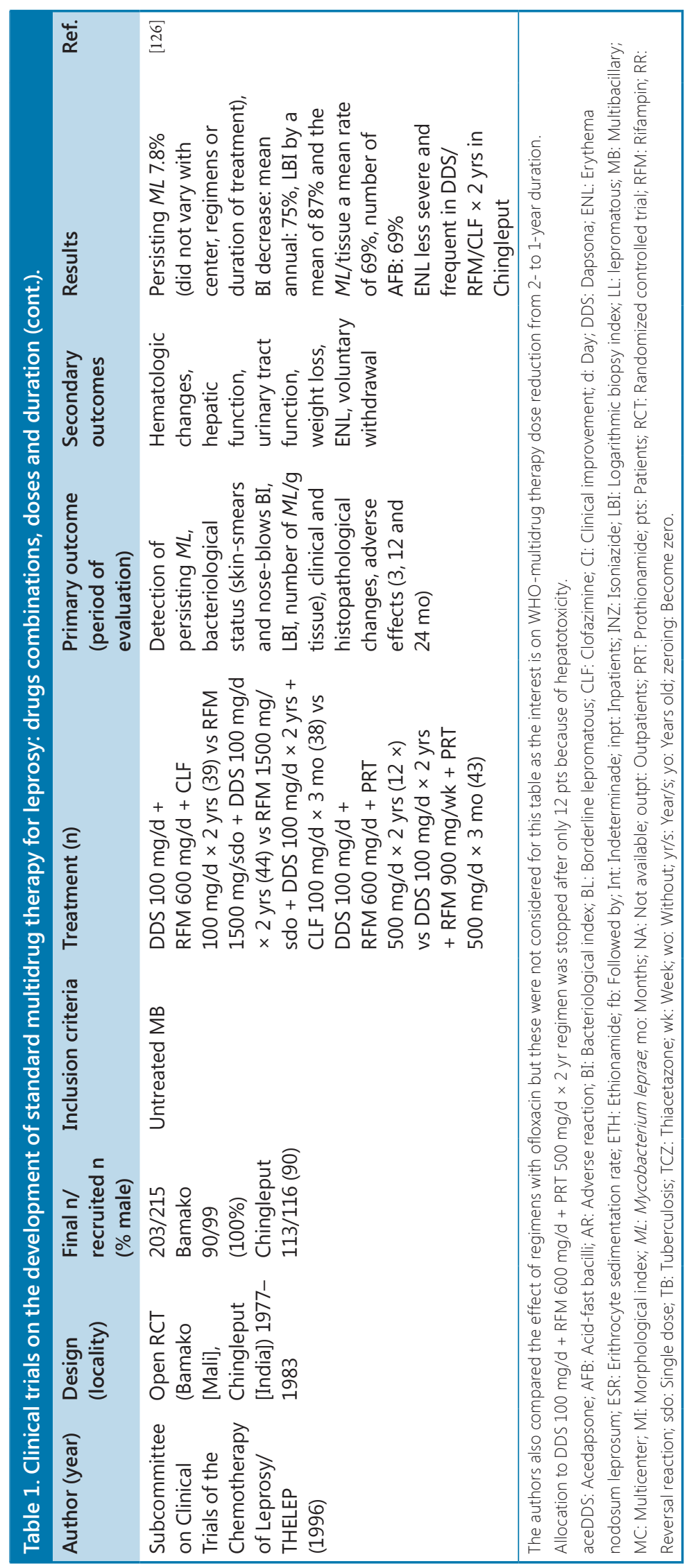

too diverse to be reliably analyzed. Significantly, there is, in fact, no clear evidence that the treatments evaluated are any different from each other in most of the trials reported.

Other authors have also pointed to the difficulties encountered in attempting to draw precise conclusions from these studies. After evaluating interventions for leprosy according to type of evidence, consistency, quality, directness and effect size, Smith and Saunderson classified studies about the effects of treatment on clinical improvement and/or relapse rates as either low or very low [72]. Thus, although widely accepted by most leprosy control programs, evidence demonstrates that any estimate of their effect is uncertain and that further research might change the estimate of that effect.

\section{Clinical trials with non-WHO-MDT drugs}

Several drugs not included in standard WHO-MDT have been recommended for treatment of leprosy patients. Screening of antibiotics known to be safe and well tolerated for their in vitro bactericidal effect against $M$. leprae [73,74], such as some fluoroquinolones, tetracyclines and macrolides, made possible the formulation of new regimens that have been tested in several trials (Table 3). Franzblau and White compared the in vitro activities of 20 fluoroquinolones against $M$. leprae and reported that OFL had excellent bactericidal activity, whereas pefloxacin and temofloxacin could have potential for treating clinical leprosy [73]. Further studies comparing different antibiotics reported that sparfloxacin and temofloxacin were highly bactericidal, while OFL, pefloxacin and lomefloxacin were the least bactericidal among the quinolones [75]. Thus, microbiological surrogate markers of disease resolution were not all consistent prior to clinical trials that followed (Tables $3 \& 4$ ).

As for the MDT trials, most of the studies demonstrating the effect of the new regimens consist of case reports, case series and field trials [52,76,77]; however, many have weak evidence of efficacy, leading to contradictory findings [78-80]. Nonetheless, suggestions of new regimens were made. At present, OFL, clarithromycin, and minocycline (MIN) are already being used as second-line antileprosy drugs for cases of adverse reactions or resistance to the standard medications [12]. However, MIN, like other tetracyclines, is not indicated for children or pregnant women.

The short course chemotherapy for tuberculosis was found to require two or more bactericidal agents [81]. Applying this concept to leprosy, treatment reduction included the use of additional bactericidal antibiotics, OFL and MIN, to RFM. Thus, single-dose RFM, OFL and MIN (ROM) was recommended to treat single skin lesion PB cases [82]. This recommendation assumes that the host response, considered efficient 


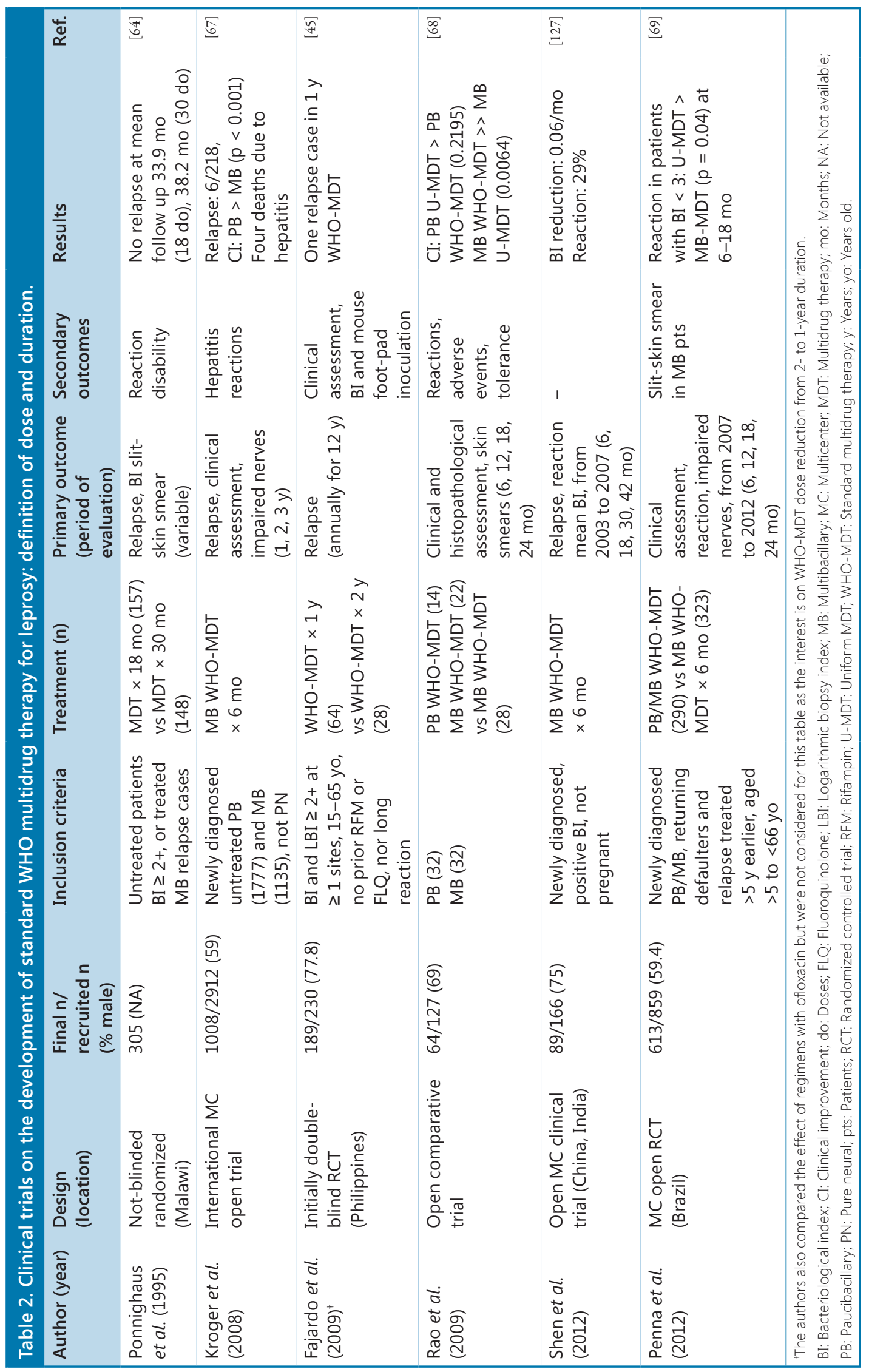




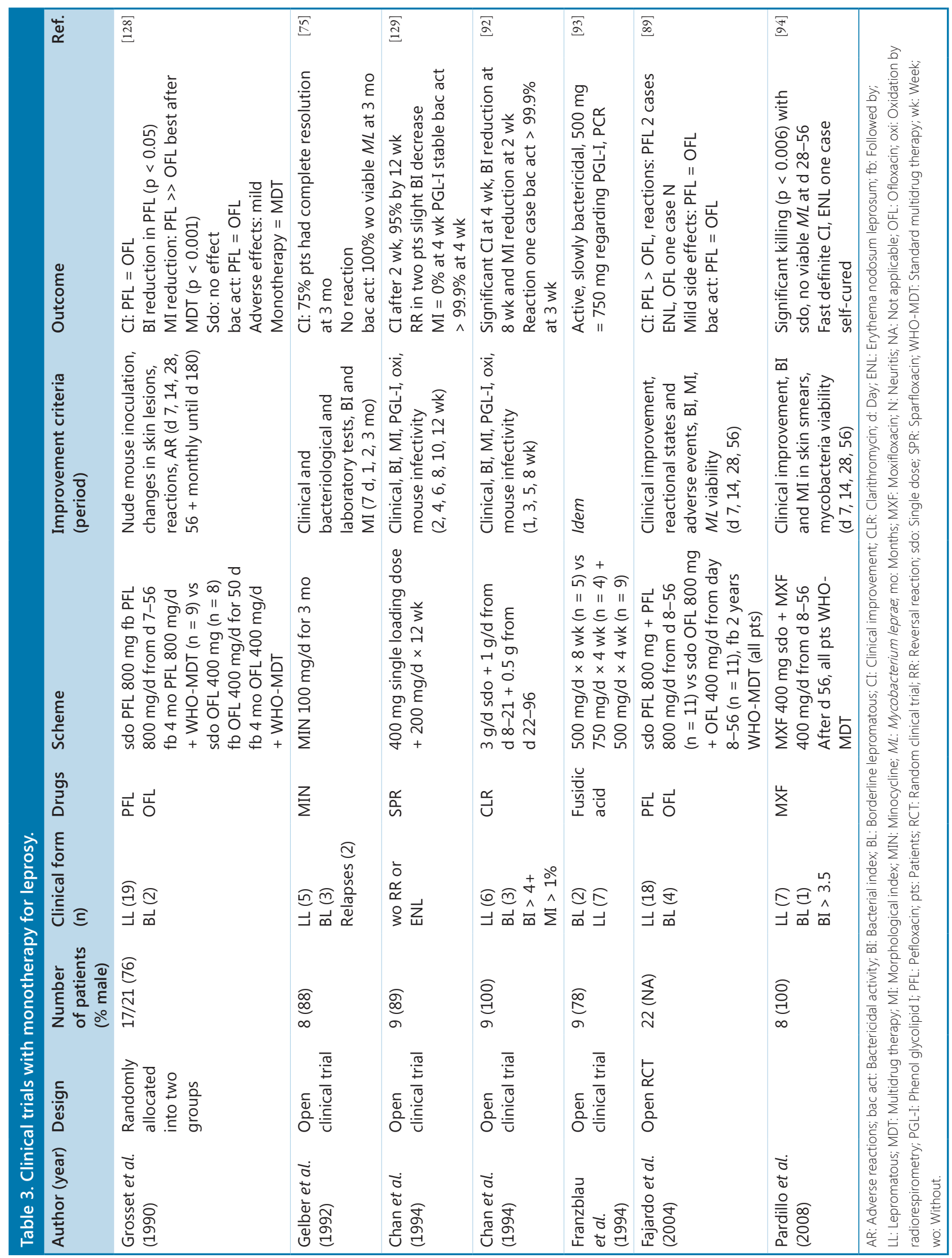


in the tuberculoid forms of the disease, will eliminate any residual viable bacteria. However, not all single lesions are $\mathrm{PB}$ [83], and not all bacterial organisms in a lesion are metabolically active, so dormant mycobacterium in the tissues would not be affected by this drug combination [84]. Would it not be more profitable to look for a sterilizing activity in the drug combination, eliminating both active and dormant organisms? Although initially believed to be promising given that ROM would dramatically reduce treatment duration and increase acceptability, it has not been shown to be superior to the current MDT $[85,86]$.

It is only recently that results have begun to be published regarding multicenter studies that had been recommended by the Steering Committee on the Chemotherapy of Mycobacterial Diseases and sponsored by the WHO/THELEP, to test these antibiotics in leprosy (Table 4). Different OFL regimens were compared against standard MB WHO-MDT in Brazil. A total of 23 relapses were diagnosed in $114 \mathrm{MB}$ patients after a 7-year period of surveillance. Most of the relapses (83\%) were registered among the 49 patients who received OFL plus RFM [42]. A well-designed and -reported double-blinded randomized trial evaluated the use of $\mathrm{ROM}$ in $\mathrm{PB}$ patients with two to five lesions. Relapse rates were significantly higher in patients treated with ROM (1.13 person/year) than in patients who received PB WHO-MDT ( 0.35 person/year) after a period of 3 years ( $\mathrm{p}=0.001 ; 95 \% \mathrm{CI}: 1.6-7.2)$ [87].

Most of the reports listed in Tables $3 \& 4$ identify the measured variables, observational methods and criteria used to assess the therapeutic response. The myriad and sometimes profound differences in types of assessments, duration periods, sequential analyses of patient progress, length of time to end point, and measured outcomes render them incomparable. Although several studies randomly assigned the patients to the several treatment groups $[42,79,88,89]$, very few explain the randomization process or provide a power statement [87,90]. Either no information on the comparable characteristics of the volunteer participants at intake was included, or the study groups were significantly different upon enrollment in some of the key end points evaluated. The study by Ji et al. is a case in point: the mean patient MI in the group receiving ROM was significantly smaller than the one receiving OFL-MIN ( $\mathrm{p}=0.001)$ [74].

Early bactericidal activity trials were developed to test various antibiotics [27,78,79,91-94]. Other studies were developed to test the drugs in small samples of patients. However, Phase I and II clinical trials require a larger sample size than those, in order to adequately determine the efficacy of intervention [95]. Thus, the observations of most of the studies are limited and their power of inference is low. If trials are not well designed from the beginning, the result is weak evidence for efficacy and the costly Phase III and IV trials are in vain.

\section{Is it possible to translate the existing preclinical trials of potential antileprosy agents into viable treatments for patients?}

Although there is little in terms of novel therapies being investigated for future treatments, preclinical studies have been developed for several new drugs such as dialkyldithiocarbamates, bipyridyl analogs, diarylquinolines and ansamycins, already tested for other mycobacteria. The macrolide derivatives roxithromycin and fosfomycin have anti-inflammatory, immunemodulatory in addition to anti- $M$. leprae activities [96], which is an advantage in antileprosy treatment.

The findings related to screening in vitro and in animal models are not always translated into clinical practice, as has been observed with regard to fusidic acid. In vitro experiments demonstrated that fusidic acid is highly bactericidal [97]; but in a Phase II trial, it was only weakly bactericidal [93]. Likewise, Ji et al. observed bactericidal activity in mice after 1 month of MDT $(99.95 \%)$ were similar to that with a single dose of RFM, clarithromycin, OFL and MIN (99.4\%) [74]. However, single-dose ROM treatment has been insufficient in humans [87].

Nonetheless, several promising drugs that have been screened in preclinical trials against $M$. leprae could offer interesting results for leprosy. Levofloxacin was found to have a twofold greater bactericidal activity than OFL and exhibited synergistic activity with rifabutin and other rifamycin analogs against $M$. leprae [98]. Other quinolones such as lomefloxacin, WIN 57273 and temafloxacin, are fully bactericidal [75]; but their effect on leprosy patients has yet to be studied. Similarly, moxifloxacin (MXF) and rifapentin (RFP) showed higher bactericidal effect than RFM [99], while the effect of gatifloxacin and linezolid was comparable to that of RFM and could be used in combination without antagonism between them [100]. Bedaquiline is a diarylquinoline with bactericidal activity against $M$. leprae comparable to that of MXF and RFP [101]. It has been found to have sterilizing activity in animal models of tuberculosis, being bactericidal against both actively metabolic and dormant mycobacteria [102].

Although many of these antibiotics are costly and only used in third-line treatments for other diseases, if an ultra-short or single-dose scheme is to be developed for leprosy, or a subgroup of patients with high bacterial loads is the focus, these drugs need to be considered.

Especially important in leprosy therapy in which a drug combination is required, is the evaluation of interactions between the different drugs. Preclinical trials need to be developed with drugs combinations prior 


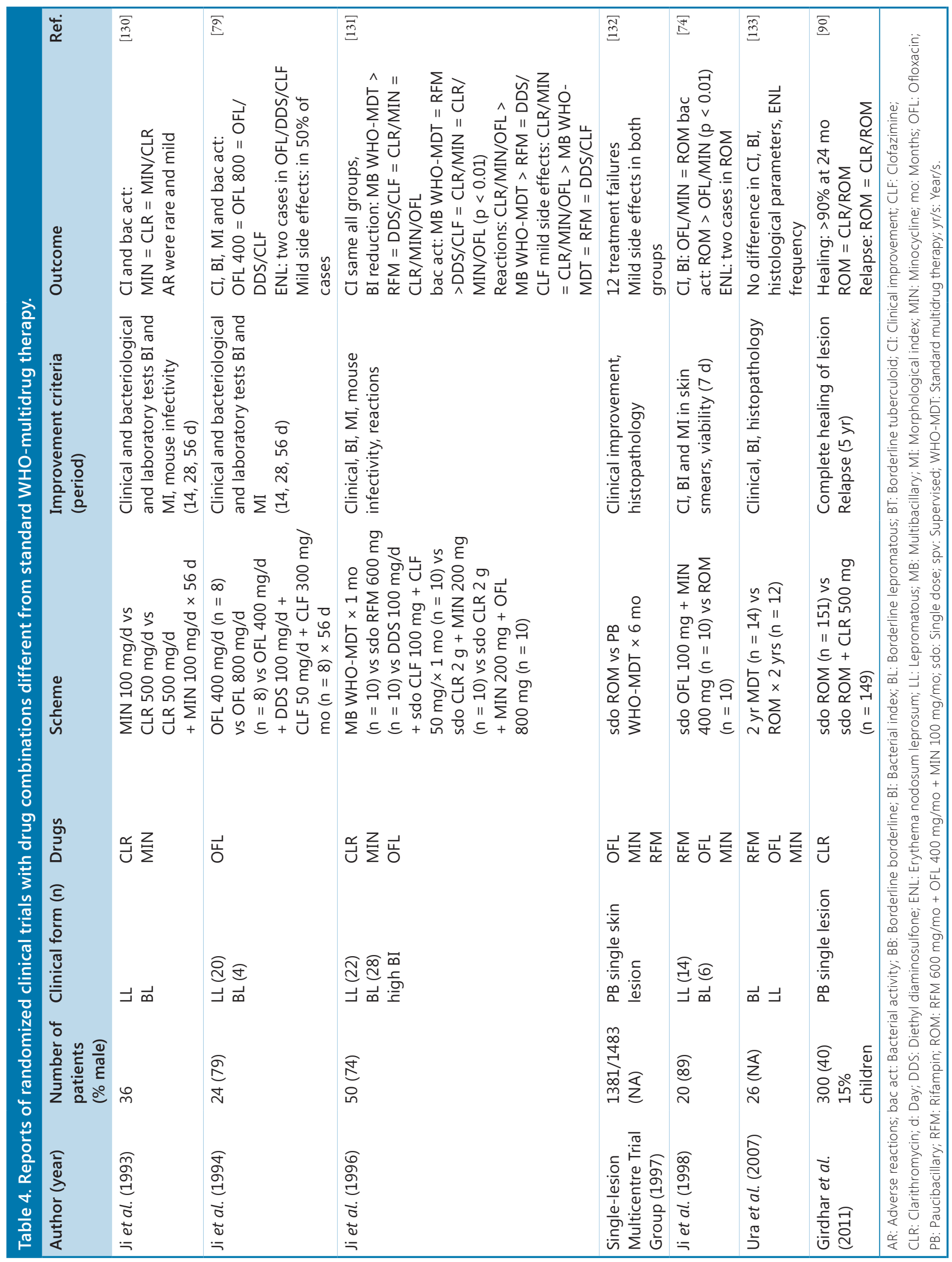




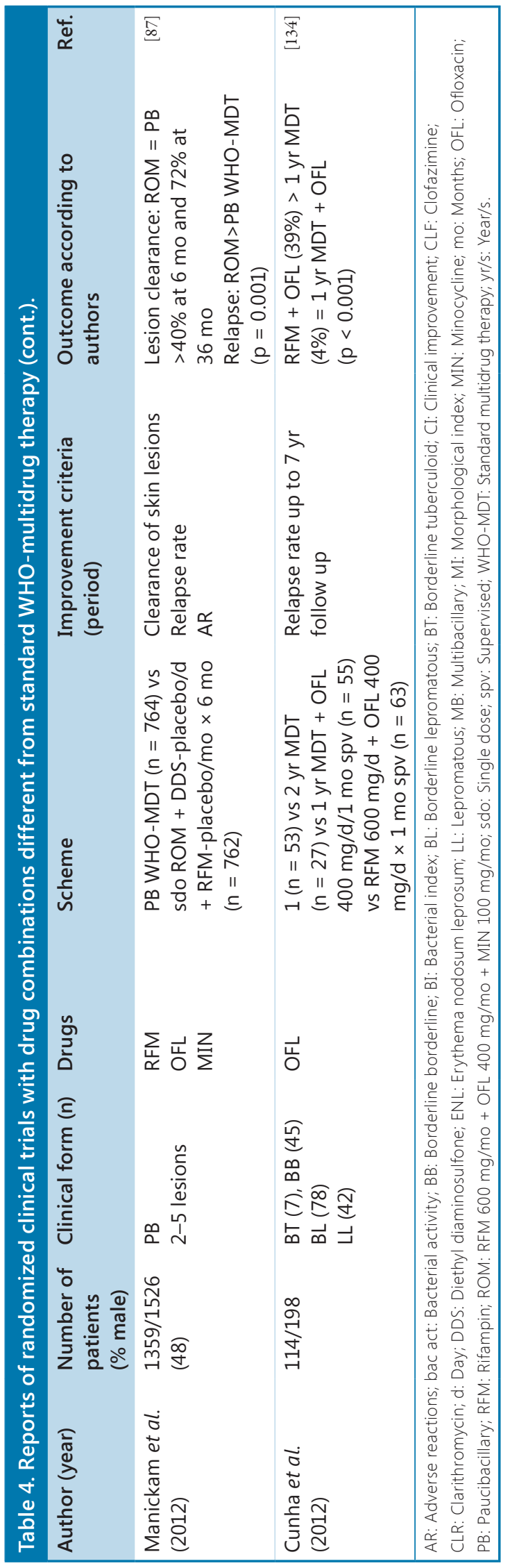

to the development of clinical trials. For instance, in the case of telithromycin, a ketolide used for community acquired pneumonia and upper respiratory tract infections, combination with RFM reduces its plasmatic concentration [202]. Drug interactions bring added complexities and challenges to the trials not encountered by those of monotherapy; for example, they can be associated with more adverse effects. The design and interpretation of combination therapy studies need to take these factors into consideration.

\section{Conclusion}

Various issues related to the design of clinical trials for antibacterial drugs against leprosy were observed in the revised literature. The methods adopted to assess patient responses to treatment as well as end point measures need to be well defined, reliable, and facilitate comparative studies.

\section{Unmet needs}

Antibacterial treatment does not exhaust the therapeutic need to treat leprosy complications such as reactions and disability. Accessibility to therapy remains a major issue in many endemic countries, especially in those with low prevalence rates. The lack of an efficient surveillance system capable of detecting relapse, drug resistance and defaulters is a matter of concern in view of the public health risk posed by the likelihood of continued transmission of infection by these cases. The development of effective drug schemes to be used for chemoprophylaxis also needs to be addressed.

The availability of second-line drugs is not uniformly and regularly distributed in endemic countries as most treatments are supported by national governments or nongovernmental organizations. As a consequence, many MB leprosy patients may have received insufficient MDT treatment after presenting adverse side effects from one of the three drugs used in the MDT standard regimen. This is a worrisome scenario as several reports have documented relapses and identified drug-resistant strains of $M$. leprae. No new regimen trials are taking place for these cases. Therefore, after introducing untested short-term treatment regimes, it is imperative to record the number of relapse cases and identify the $M$. leprae strains involved.

The nerve function deterioration that may occur after completion of WHO-MDT [103] has generated distrust regarding the efficacy of MDT. It is difficult for local health workers and patients to accept being pronounced cured after release from treatment if nerve impairment continues to progress and successive reactions require further medical care. Some authors have argued that 'cure rates' should be replaced by 'treatment completion rates' [60]. Considering the current 
WHO target for reduction of deformities by the year 2020 , there is an urgent need to intensify research to develop an effective treatment and address nerve function impairment head on.

\section{Recommendations}

Cure involves much more than the killing of bacteria and the disappearance of skin lesions and peripheral nerve involvement. A person affected by leprosy has other medical needs that may or may not be the result of $M$. leprae infection, but are a product of disability, social or cultural background. For future trials, it would be desirable to have a well-defined and reliable clinician-reported outcome instrument in addition to biomarkers for $\mathrm{PB}$ patients.

Known treatments have been proven to effectively kill circulating bacteria but not persistent ones. To achieve sterilizing activity in patients remains one of the biggest challenges in developing useful regimens for leprosy. Persister organisms are a fraction of an antibiotic-treated bacterial population that are refractory to killing without becoming genetically resistant [104]. Recent advances in mycobacterial pathogenesis demonstrate the ability of some species to induce modifications in the host cell to improve the niche and ensure dissemination [105], as well as to modify their adaptative response to the pressures exerted by prolonged drug exposure [106]. These epigenetic effects may also be present in $M$. leprae.

Trials with an adequate sample size that adhere to the principles of good clinical practice [13] and include the well-established $\mathrm{PB}$ and $\mathrm{MB}$ WHO-MDT regimens as controls are required to have good evidence of the effect of new drug combinations. Noninferiority trial designs could be a resourceful option for testing short schemes in leprosy and they may be more feasible than superiority trials. Efficacy decisions need to be based on consistent clinical and bacteriological improvement and take relapses into account. The intent-to-treat correction could be used to protect against bias and strengthen study conclusions. The use of placebo in addition to the standard MDT to test against other combination therapies would also strengthen the observations. It is recommended that protocol designs follow the Standard Protocol Items: Recommendations for Interventional Trials 2013 statement to ensure the designs contain the requisite information for critical appraisal and interpretation [107].

Better end points should also be designed for clinical trials in leprosy. New molecular tests that could determine the viability of relatively small bacterial numbers would be of particular interest. Comparing the amounts of $M$. leprae RNA and DNA in tissue samples, such as the $16 \mathrm{~S}$ rRNA/RLEP ratio, has already been proven effective in determining bacterial viability [30]. These molecular tests are less time-consuming and expensive than traditional in vitro bacterial metabolism analyses. Other promising surrogate end points could be the serological biomarkers currently under investigation. Several $M$. leprae recombinant proteins (LID-1, ML2028, ML0286 and ML2038) elicit an antibody response in both $\mathrm{PB}$ and MB cases while the response rapidly declines after completion of MDT even in patients with a high initial BI [23].

Treatment of mycobacterial infection in the nerves is still far from satisfactory. Understanding the pathogenesis of $M$. leprae-induced nerve injury may pave the way toward new pathways in leprosy therapeutics. For example, trastuzumab, a humanized monoclonal ErbB2 antibody, has been proposed as a potential agent as in vitro studies demonstrated it was effectively able to block the binding of $M$. leprae to Schwann cells [108].

Any considerations regarding new antibiotics also need to address their ability to cross the blood-nerve barrier and their interaction with antireactional drugs. It is well established that drug concentrations in the tissues vary according to the presence or absence of inflammation. In the course of a CNS infection, drug concentrations found during early infection and its resolution are different from those found when the meninges are inflamed. In addition, penetration and concentration may be affected by other drugs. Molecular size, lipophilicity, plasma protein binding and active transport affect the penetration of antiinfectives into the cerebrospinal fluid and brain tissue [19]. Thus, it is highly desirable to obtain effective antibiotic concentrations in the nerve compartments, not only of inflamed, but also of normal nerve tissue. Carefully designed experiments are needed to assess the pharmacokinetics of antibiotics at the blood-nerve barrier and their pharmacodynamic properties in the nerve tissue. This knowledge may help to improve the treatment of $M$. leprae nerve infection.

Instead of only targeting the infectious agent, a different potential therapeutic approach might involve the induction of a strong adaptive immune response in the patient to limit the infection and promote healing, for example, by prescribing vitamin $\mathrm{D}$ [109].

All of the above-cited elements need to be considered in the implementation of new treatment regimens. Furthermore, since the general trend is to unify and shorten the present regimens, the probability of increasing complications post-MDT should be measured. Many studies with promising positive results have not yet been implemented while others have not been published. The cost and operational factors involved in new treatment regimens must be considered, keeping 
in mind the priority of early case detection, especially if zero transmission is to be achieved.

In agreement with other authors that suggest the use of highly bactericidal agents to replace bacteriostatic DDS or CLF [52], a more bactericidal MDT definitely needs to be used in the treatment of MB cases with a high bacterial index. Several potential candidate drugs are already in the market. The combination of RFP, MXF and MIN has been the most potent anti-M. leprae drug scheme found so far. MXF presents the advantage of having good penetration in skin macrophages, especially in infected ones [110], and has already been trialled for combination therapy in tuberculosis [111]. Finally, a recently approved drug for the treatment of resistant tuberculosis, bedaquiline [203], or the long known telithromycin could also be tried in combination regimens. The use of highly bactericidal antibiotics could also allow for a considerable reduction of treatment duration for the other forms of leprosy.

Nevertheless, among the drugs currently in use, CLF, in spite of only being bacteriostatic against $M$. leprae, possesses anti-inflammatory and immunosuppressive properties that render it still of interest [112]. It is used for chronic inflammatory diseases such as pyoderma gangrenosum [113] and systemic lupus erythematosus [114]. However, it reduces the macrophage half-life, which might lead to reduction of bacterial clearance, and produces minor adverse effects. Still, several analogs have shown improved properties and reduced adverse effects that could be used in the drugs combination [115].
The Nippon Foundation and Novartis currently provide financial support for WHO-MDT supply and will continue to do so until 2020 with additional donations and logistics support from the Novartis Foundation for Sustainable Development [204]. Until that time, alternative drug combinations need to be sufficiently screened and evaluated. To be of advantage to replace the standard WHO-MDT, the new combination must be the shortest possible, as well as a simple and, consequently, affordable treatment.

\section{Future perspective}

The use of new, highly bactericidal antibiotics in combination with drugs that induce a strong adaptive immune response may prove effective to finally reach sterilizing effect against $M$. leprae. Furthermore, the inclusion of novel serological biomarkers and molecular testing will be helpful in proving the absence of both circulating and persister organisms in patients treated with these new treatment regimens, thereby reducing the need for long follow-up periods for confirming their effect.

\footnotetext{
Financial \& competing interests disclosure

The authors have no relevant affliations or financial involvement with any organization or entity with a financial interest in or financial conflict with the subject matter or materials discussed in the manuscript. This includes employment, consultancies, honoraria, stock ownership or options, expert testimony, grants or patents received or pending, or royalties.

No writing assistance was utilized in the production of this manuscript.
}

\section{Executive summary}

\section{Principles of leprosy treatment}

- Leprosy is caused by Mycobacterium leprae infection and the particular immunological response elicited, producing a spectrum of clinical forms and immune reactions.

- The current established cure parameter for leprosy imposes many difficulties for defining comparable, clear-cut end points for clinical trials.

Unmet needs

- Validated surrogate end points to evaluate the effect of new regimens in clinical trials such as serological and molecular biomarkers are needed.

- Defining objective and comparable parameters to evaluate the therapeutic effect in all patients is a cornerstone of clinical trials in leprosy.

- To date, no standardized, reproducible and consistent end point has been used to evaluate the meaning of a cure in leprosy.

\section{Recommendations}

- Although little is being investigated in terms of novel therapies for the treatment of leprosy, there are few drug combinations that could be explored in well-designed clinical trials that follow the Standard Protocol Items: Recommendations for Interventional Trials 2013.

- Short new schemes need to include a combination of two or more highly bactericidal drugs that also have an immune/antiinflammatory effect, such as rifapentin and moxyfloxacin, in combination with drugs that induce a strong adaptive immune response.

- Long surveillance periods after trials of uniform and standard multidrug therapy must be ensured in order to allow firm conclusions regarding relapse rates.

- New regimens are required for patients, especially children, who are resistant to or do not tolerate any of the drugs in the current multidrug therapy. 


\section{References}

Papers of special note have been highlighted as:

- of interest

-. of considerable interest

1 WHO. Leprosy update, 2011. Wkly Epidemiol. Rec. 86(36), 389-399 (2011).

2 Faget G, Jonhansen FA, Dinah JF, Prejean BM, Eccles C. The Promin treatment of leprosy: a progress report. Public Health Reports 58, 1729-1741 (1943).

3 Jacobson R. Treatment of leprosy. In: Leprosy. Medicine in the Tropics Series. Hastings RC (Ed.). Churchill Livingstone, Oxford, UK, 193-222 (1985).

4 WHO. World Health Organization Expert Committee on Leprosy. Fifth Report. WHO Tech. Rep. Ser. 607 (1977).

5 Jacobson RR, Gatt P. Can leprosy be eradicated with chemotherapy? An evaluation of the Malta Leprosy Eradication Project. Lepr. Rev. 79(4), 410-415 (2008).

6 Pritze S, Alvarenga AE, Leguizamon O, Haubitz I. Isoprodian and rifampicin in the treatment of leprosy: a descriptive evaluation of therapy durations in 475 Paraguayan leprosy patients. Chemotherapy 35(5), 373-382 (1989).

7 WHO. Chemotherapy of leprosy for control programmes. World Health Organ. Tech. Rep. Ser. 675, 1-33 (1982)

8 WHO. WHO Expert Committee on Leprosy. World Health Organ. Tech. Rep. Ser. 768, 1-51 (1988).

9 Rao PS. A study on non-adherence to MDT among leprosy patients. Indian J. Lepr. 80(2), 149-154 (2008).

10 Van Brakel W, Cross H, Declercq E et al. Review of leprosy research evidence (2002-2009) and implications for current policy and practice. Lepr. Rev. 81(3), 228-275 (2010).

11 Prasad PV, Kaviarasan PK. Leprosy therapy, past and present: can we hope to eliminate it? Indian J. Dermatol. 55(4), 316-324 (2010).

12 WHO. WHO Expert Committee on Leprosy. World Health Organ. Tech. Rep. Ser. (968), 1-61, (2012).

13 WHO. Report on third meeting of the WHO technical advisory group on elimination of leprosy. WHO, Brasília, Brazil, 2002.

14 Ridley DS, Jopling WH. Classification of leprosy according to immunity. A five-group system. Int. J. Lepr. Other Mycobact. Dis. 34(3), 255-273 (1966).

15 Shetty VP, Suchitra K, Uplekar MW, Antia NH. Persistence of Mycobacterium leprae in the peripheral nerve as compared to the skin of multidrug-treated leprosy patients. Lepr. Rev. 63(4), 329-336 (1992).

16 Nery JA, Vieira LM, De Matos HJ, Gallo ME, Sarno EN. Reactional states in multibacillary Hansen disease patients during multidrug therapy. Rev. Inst. Med. Trop. Sao Paulo 40 (6), 363-370 (1998).

17 Sarno EN, Sampaio EP. The role of inflammatory cytokines in the tissue injury of leprosy. Int. J. Lepr. Other Mycobact. Dis. 64(4 Suppl.), S69-S73; discussion S73-S64 (1996).

18 Scollard DM, Adams LB, Gillis TP, Krahenbuhl JL, Truman RW, Williams DL. The continuing challenges of leprosy. Clin. Microbiol. Rev. 19(2), 338-381 (2006).

19 Nau R, Sorgel F, Eiffert H. Penetration of drugs through the blood-cerebrospinal fluid/ blood-brain barrier for treatment of central nervous system infections. Clin. Microbiol. Rev. 23(4), 858-883 (2010).

20 Shetty VP, Khambati FA, Ghate SD, Capadia GD, Pai VV, Ganapati R. The effect of corticosteroids usage on bacterial killing, clearance and nerve damage in leprosy; part 3 - study of two comparable groups of 100 multibacillary (MB) patients each, treated with MDT + steroids vs MDT alone, assessed at 6 months post-release from 12 months MDT. Lepr. Rev. 81(1), 41-58 (2010).

21 Downing JE, Miyan JA. Neural immunoregulation: emerging roles for nerves in immune homeostasis and disease. Immunol. Today 21(6), 281-289 (2000).

22 Kaimal S, Thappa DM. Relapse in leprosy. Indian J. Dermatol. Venereol. Leprol. 75(2), 126-135 (2009).

23 Spencer JS, Duthie MS, Geluk A et al. Identification of serological biomarkers of infection, disease progression and treatment efficacy for leprosy. Mem. Inst. Oswaldo Cruz 107(Suppl. 1), 79-89 (2012)

24 Brito Mde F, Ximenes RA, Gallo ME, Buhrer-Sekula S. Association between leprosy reactions after treatment and bacterial load evaluated using anti PGL-I serology and bacilloscopy. Rev. Soc. Bras. Med. Trop. 41(Suppl. 2), 67-72 (2008).

25 Penna ML, Buhrer-Sekula S, Pontes MA, Cruz R, Goncalves Hde S, Penna GO. Primary results of clinical trial for uniform multidrug therapy for leprosy patients in Brazil (U-MDT/CT-BR): reactions frequency in multibacillary patients. Leprosy Rev. 83(3), 308-319 (2012).

26 Katoch VM, Katoch K, Ramanathan U et al. Effect of chemotherapy on viability of
Mycobacterium leprae as determined by ATP content, morphological index and FDA-EB fluorescent staining. Int. J. Lepr. Other Mycobact. Dis. 57(3), 615-621 (1989).

27 Chan GP, Garcia-Ignacio BY, Chavez VE et al. Clinical trial of sparfloxacin for lepromatous leprosy. Antimicrob. Agents Chemother. 38(1), 61-65 (1994).

28 Moura RS, Calado KL, Oliveira ML, Buhrer-Sekula S. Leprosy serology using PGL-I: a systematic review. Rev. Soc. Bras. Med. Trop. 41(Suppl. 2), 11-18 (2008).

29 Buhrer-Sekula S, Illarramendi X, Teles RB et al. The additional benefit of the ML Flow test to classify leprosy patients. Acta Trop. 111(2), 172-176 (2009).

30 Martinez AN, Lahiri R, Pittman TL et al. Molecular determination of Mycobacterium leprae viability by use of real-time PCR. J. Clin. Microbiol. 47(7), 2124-2130 (2009).

31 WHO. Chemotherapy of leprosy for control programmes. WHO Tech. Rep. Ser. 675, 1-33 (1982).

32 Legendre DP, Muzny CA, Swiatlo E. Hansen's disease (leprosy): current and future pharmacotherapy and treatment of diseaserelated immunologic reactions. Pharmacotherapy 32(1), 27-37 (2012).

33 Mandell Gl, Sandle MA. Drugs used in the chemotherapy of tuberculosis and leprosy. In: Goodman and Gilman's: The Pharmacological Basis of Therapeutics. Brunton LL, Chabner BA, Knollmann BC (Eds). Pergamon Press, NY, USA, 1149-1161 (1990).

34 Deps PD, Nasser S, Guerra P, Simon M, Birshner Rde C, Rodrigues LC. Adverse effects from multi-drug therapy in leprosy: a Brazilian study. Lepr. Rev. 78(3), 216-222 (2007).

35 Goulart IM, Arbex Gl, Carneiro MH, Rodrigues MS, Gadia R. Adverse effects of multidrug therapy in leprosy patients: a five-year survey at a Health Center of the Federal University of Uberlandia. Rev. Soc. Bras. Med. Trop. 35(5), 453-460 (2002).

36 Leta G, Simas M, Oliveira M, Gomes M. Síndrome de hipersensibilidade à dapsona: revisão sistemática dos critérios diagnósticos. Hansen. Int. 28(1), 79-84 (2003).

37 Lorenz M, Wozel G, Schmitt J. Hypersensitivity reactions to dapsone: a systematic review. Acta Derm. Venereol. 92(2), 194-199 (2012).

38 Chen Y-C, Chiu H-C, Chu C-Y. Drug reaction with eosinophilia and systemic symptoms: a retrospective study of 60 cases. Arch. Dermatol. 146(12), 1373-1379 (2010). 
39 WHO. Surveillance of drug resistance in leprosy: 2010. Wkly Epidemiol. Rec. 86(23), 237 (2010).

40 Balagon MF, Cellona RV, Cruz E et al. Long-term relapse risk of multibacillary leprosy after completion of 2 years of multiple drug therapy (WHO-MDT) in Cebu, Philippines. Am. J. Trop. Med. Hyg. 81(5), 895-899 (2009).

41 Haldar A, Mahapatra BS, Mundle M, Haldar $S$, Saha AK. A study of relapse after MDT in a district in West Bengal, India. Indian J. Lepr. 75(1), 1-8 (2003).

42 Rocha A, Cunha M, Diniz L. Drug and multidrug resistance among mycobacterium leprae isolates from Brazilian relapsed leprosy patients. J. Clin. Microbiol. 50, 1912-1917. (2012).

43 Gebre S, Saunderson P, Byass P. Relapses after fixed duration multiple drug therapy: the AMFES cohort. Lepr. Rev. 71(3), 325-331 (2000).

44 Ji B. Does dapsone resistance really matter in the MDT era? Int. J. Lepr. Other Mycobact. Dis. 69(1), 54-55 (2001).

45 Fajardo TT, Villahermosa L, Pardillo FE et al. A comparative clinical trial in multibacillary leprosy with long-term relapse rates of four different multidrug regimens. Am. J. Trop. Med. Hyg. 81(2), 330-334 (2009).

46 Ramu G. Clinical features and diagnosis of relapses in leprosy. Indian J. Lepr. 67(1), 45-59 (1995).

47 Desikan KV, Sundaresh P, Tulasidas I, Rao PV. An 8-12 year follow-up of highly bacillated Indian leprosy patients treated with WHO multi-drug therapy. Lepr. Rev. 79(3), 303-310 (2008).

48 Guerrero-Guerrero MI, Muvdi-Arenas S, Leon-Franco CI. Relapses in multibacillary leprosy patients: a retrospective cohort of 11 years in Colombia. Leprosy Rev. 83(3), 247-260 (2012)

49 Poojabylaiah M, Marne Rb, Varikkodan R, Bala N, Dandakeri S, Martis J. Relapses in multibacillary leprosy patients after multidrug therapy. Lepr. Rev. 79(3), 320-324 (2008).

50 Shaw IN, Natrajan MM, Rao GS, Jesudasan K, Christian M, Kavitha M. Long-term follow up of multibacillary leprosy patients with high $\mathrm{BI}$ treated with $\mathrm{WHO} /$ MDT regimen for a fixed duration of two years. Int. J. Lepr. Other Mycobact. Dis. 68(4), 405-409 (2000).

51 Ji B. Discussion document: a review of evidence on MB relapse rate after MDT. ILEP Technical Commission (2005).
52 Gelber RH, Grosset J. The chemotherapy of leprosy: an interpretive history. Lepr. Rev. 83(3), 221-240 (2012).

53 Oliveira M. Hanseníase: cronificação da doença por insuficiência terapêutica. Hansen Int. 36(1), 61 (2011).

54 Montoya D, Cruz D, Teles RM et al. Divergence of macrophage phagocytic and antimicrobial programs in leprosy. Cell Host Microbe 6(4), 343-353 (2009).

55 Illarramendi X, Sales A, Nery J, Sampaio E, Sarno E. Need of new immunosuppressive agents for the treatment of leprosy reactions. Presented at: 13th International Congress of Immunology. Rio de Janeiro, Brazil, 21-25 August 2007.

56 Da Silva Rocha A, Cunha M, Diniz LM et al. Drug and multidrug resistance among Mycobacterium leprae isolates from Brazilian relapsed leprosy patients. J. Clin. Microbiol. 50(6), 1912-1917 (2012).

57 Matsuoka M, Suzuki Y, Garcia IE et al. Possible mode of emergence for drug-resistant leprosy is revealed by an analysis of samples from Mexico. Jpn J. Infect. Dis. 63(6), 412-416 (2010).

58 Williams DL, Gillis TP. Drug-resistant leprosy: monitoring and current status. Lepr. Rev. 83(3), 269-281 (2012).

59 WHO. Report of the WHO workshop on sentinel surveillance for drug resistance in leprosy 20-22 October 2008; Hanoi, Vietnam. Indian J. Lepr. 81(1), 43-54 (2009).

60 Prasad PV, Kaviarasan PK. Leprosy therapy, past and present: can we hope to eliminate it? Indian J. Dermatol. 55(4), 316-324 (2011).

61 WHO. WHO Expert Committee on Leprosy. World Health Organ. Tech. Rep. Ser. 874, 1-43 (1998).

62 Ji B. Why multidrug therapy for multibacillary leprosy can be shortened to 12 months. Lepr. Rev. 69(2), 106-109 (1998).

63 Sales AM, Sabroza PC, Nery JA, Duppre NC, Sarno EN. No difference in leprosy treatment outcomes comparing 12 - and 24-dose multidrug regimens: a preliminary study. Cad. Saude Publica 23(4), 815-822 (2007).

64 Ponnighaus JM, Boerrigter G. Are 18 doses of WHO/MDT sufficient for multibacillary leprosy; results of a trial in Malawi. Int. J. Lepr. Other Mycobact. Dis. 63(1), 1-7 (1995).

65 Gallo ME, Alvim MF, Nery JA, Albuquerque EC, Sarno EN. Two multidrug fixed-dosage treatment regimens with multibacillary leprosy patients. Indian J. Lepr. 68(3), 235-245 (1996).
66 Kumar B, Dogra S, Kaur I. Epidemiological characteristics of leprosy reactions: 15 years experience from north India. Int. J. Lepr. Other Mycobact. Dis. 72(2), 125-133 (2004).

67 Kroger A, Pannikar V, Htoon MT et al. International open trial of uniform multi-drug therapy regimen for 6 months for all types of leprosy patients: rationale, design and preliminary results. Trop. Med. Int. Health 13(5), 594-602 (2008).

68 Rao PN, Suneetha S, Pratap DV. Comparative study of uniform-MDT and WHO MDT in Pauci and multi bacillary leprosy patients over 24 months of observation. Lepr. Rev. 80(2), 143-155 (2009).

69 Penna GO, Pontes MA, Cruz R, Goncalves Hde S, Penna ML, Buhrer-Sekula S.

A clinical trial for uniform multidrug therapy for leprosy patients in Brazil: rationale and design. Mem. Inst. Oswaldo Cruz 107(Suppl. 1), 22-27 (2012).

70 Gonçalves Hde S, Pontes MA, BuhrerSekula $S$ et al. Brazilian clinical trial of uniform multidrug therapy for leprosy patients: the correlation between clinical disease types and adverse effects. Mem. Inst. Oswaldo Cruz 107(Suppl. 1), 74-78 (2012).

71 Dacso MM, Jacobson RR, Scollard DM, Stryjewska BM, Prestigiacomo JF. Evaluation of multi-drug therapy for leprosy in the United States using daily rifampin. South Med. J. 104(10), 689-694 (2011).

72 Smith WC, Saunderson P. Leprosy. Clin. Evid. (Online) 2010 (pii) 0915 (2010).

-. Systematic review regarding the effectiveness and safety of multidrug and multiple dose therapy.

73 Franzblau SG, White KE. Comparative in vitro activities of 20 fluoroquinolones against Mycobacterium leprae. Antimicrob. Agents Chemother. 34(2), 229-231 (1990).

74 Ji B, Sow S, Perani E, Lienhardt C, Diderot V, Grosset J. Bactericidal activity of a single-dose combination of ofloxacin plus minocycline, with or without rifampin, against Mycobacterium leprae in mice and in lepromatous patients. Antimicrob. Agents Chemother. 42(5), 1115-1120 (1998).

75 Gelber RH, Iranmanesh A, Murray L, Siu P, Tsang M. Activities of various quinolone antibiotics against Mycobacterium leprae in infected mice. Antimicrob. Agents Chemother. 36(11), 2544-2547 (1992).

76 Gelber RH. Chemotherapy of lepromatous leprosy: recent developments and prospects for the future. Eur. J. Clin. Microbiol. Infect. Dis. 13(11), 942-952 (1994). 
77 Gelber RH: Successful treatment of a lepromatous patient with clarithromycin. Int. J. Lepr. Other Mycobact. Dis. 63(1), 113-115 (1995).

78 Grosset JH, Ji BH, Guelpa-Lauras CC, Perani EG, N’Deli LN. Clinical trial of pefloxacin and ofloxacin in the treatment of lepromatous leprosy. Int. J. Lepr. Other Mycobact. Dis. 58(2), 281-295 (1990).

79 Ji B, Perani EG, Petinom C, N’Deli L, Grosset JH. Clinical trial of ofloxacin alone and in combination with dapsone plus clofazimine for treatment of lepromatous leprosy. Antimicrob. Agents Chemother. 38(4), 662-667 (1994).

80 Gelber RH. Another view of the therapy of leprosy. Antimicrob. Agents Chemother. 42(12), 3334-3336 (1998).

81 Global Alliance for TB Drug Development. Scientific Blueprint for Tuberculosis Drug Development. Tuberculosis 81(1), 1-52 (2001).

82 WHO. Report of the ninth meeting of the WHO Technical Advisory Group on Leprosy Control: Cairo, Egypt, 6-7 March 2008. Lepr. Rev. 79(4), 452-470 (2008).

83 Rao PN, Suneetha S, Pratap DV. Changes in the size and number of skin lesions in $\mathrm{PB}$ leprosy on treatment and follow-up. Lepr. Rev. 82(3), 244-252 (2011).

84 Katoch VM. Is there a microbiological rationale for single-dose treatment of leprosy? Lepr. Rev. 69(1), 2-5 (1998).

85 Setia MS, Shinde SS, Jerajani HR, Boivin JF. Is there a role for rifampicin, ofloxacin and minocycline (ROM) therapy in the treatment of leprosy? Systematic review and metaanalysis. Trop. Med. Int. Health 16(12), 1541-1551 (2011).

- Analyzes the efficacy of rifampin, ofloxacin and minocycline therapy in paucibacillary and multibacillary patients from the results given in 14 studies, and suggests that multiple doses may be useful for both groups of patients.

86 Alam K, Butlin CR, Pahan D, Kumar S, Chowdhury. Long-term follow-up of ROM treated cases. Lepr. Rev. 78(2), 160 (2007).

87 Manickam P, Nagaraju B, Selvaraj V et al. Efficacy of single-dose chemotherapy (rifampicin, ofloxacin and minocyclineROM) in PB leprosy patients with 2 to 5 skin lesions, India: randomised double-blind trial. Indian J. Lepr. 83, 195 (2012).

88 Ji B, Jamet P, Perani Eg et al. Bactericidal activity of single dose of clarithromycin plus minocycline, with or without ofloxacin, against Mycobacterium leprae in patients.
Antimicrob. Agents Chemother. 40(9), 2137-2141 (1996).

89 Fajardo TT Jr, Villahermosa LG, Cruz EC et al. A clinical trial of pefloxacin and ofloxacin in lepromatous leprosy. Lepr. Rev. 75(4), 389-397 (2004).

90 Girdhar A, Kumar A, Girdhar BK. A randomised controlled trial assessing the effect of adding clarithromycin to rifampicin, ofloxacin and minocycline in the treatment of single lesion paucibacillary leprosy in Agra District, India. Lepr. Rev. 82(1), 46-54 (2011).

91 Gelber RH, Fukuda K, Byrd S et al. A clinical trial of minocycline in lepromatous leprosy. BMJ 304(6819), 91-92 (1992).

92 Chan GP, Garcia-Ignacio BY, Chavez VE et al. Clinical trial of clarithromycin for lepromatous leprosy. Antimicrob. Agents Chemother. 38(3), 515-517 (1994).

93 Franzblau SG, Chan GP, Garcia-Ignacio BG et al. Clinical trial of fusidic acid for lepromatous leprosy. Antimicrob. Agents Chemother. 38(7), 1651-1654 (1994).

94 Pardillo FE, Burgos J, Fajardo TT et al. Powerful bactericidal activity of moxifloxacin in human leprosy. Antimicrob. Agents Chemother. 52(9), 3113-3117 (2008).

95 Stanley K. Evaluation of randomized controlled trials. Circulation 115(13), 1819-1822 (2007).

96 Gidoh M. The control leprous peripheral neuropathy and chemotherapy. Nihon Hansenbyo Gakkai Zasshi 68(2), 83-86 (1999).

97 Franzblau SG, Biswas AN, Harris EB. Fusidic acid is highly active against extracellular and intracellular Mycobacterium leprae. Antimicrob. Agents Chemother. 36(1), 92-94 (1992).

98 Dhople AM, Ibanez MA. The in vitro activities of novel benzoxazinorifamycins against Mycobacterium leprae. J. Antimicrob. Chemother. 35(4), 463-471 (1995).

99 Consigny S, Bentoucha A, Bonnafous P, Grosset J, Ji B. Bactericidal activities of HMR 3647, moxifloxacin, and rifapentine against Mycobacterium leprae in mice. Antimicrob. Agents Chemother. 44(10), 2919-2921 (2000).

100 Burgos J, De La Cruz E, Paredes R, Andaya $\mathrm{CR}$, Gelber RH. The activity of several newer antimicrobials against logarithmically multiplying $M$. leprae in mice. Leprosy Review 82(3), 253-258 (2011).

101 Gelber R, Andries K, Paredes RM, Andaya CE, Burgos J. The diarylquinoline R207910 is bactericidal against Mycobacterium leprae in mice at low dose and administered intermittently. Antimicrob. Agents Chemother. 53(9), 3989-3991 (2009).

102 Koul A, Vranckx L, Dendouga N et al. Diarylquinolines are bactericidal for dormant mycobacteria as a result of disturbed ATP homeostasis. J. Biol. Chem. 283(37), 25273-25280 (2008).

103 Oliveira RB, Ochoa MT, Sieling PA et al. Expression of Toll-like receptor 2 on human Schwann cells: a mechanism of nerve damage in leprosy. Infect. Immun. 71(3), 1427-1433 (2003).

104 Jermy A. Bacterial physiology: no rest for the persisters. Nat. Rev. Microbiol. 11(3), 148-149 (2013).

105 Masaki T, Qu J, Cholewa-Waclaw J, Burr K, Raaum R, Rambukkana A. Reprogramming adult Schwann cells to stem cell-like cells by leprosy bacilli promotes dissemination of infection. Cell 152(1-2), 51-67 (2013).

106 Wakamoto Y, Dhar N, Chait R et al. Dynamic persistence of antibiotic-stressed mycobacteria. Science 339(6115), 91-95 (2013).

107 Chan AW, Tetzlaff JM, Altman DG, Dickersin K, Moher D. SPIRIT 2013: new guidance for content of clinical trial protocols. Lancet 381(9861), 91-92 (2013).

108 Noon LA, Lloyd AC. Treating leprosy: an Erb-al remedy? Trends Pharmacol. Sci. 28(3), 103-105 (2007).

109 Liu PT, Wheelwright M, Teles R et al. MicroRNA-21 targets the vitamin D-dependent antimicrobial pathway in leprosy. Nat. Med. 18(2), 267-273 (2012).

110 Seral C, Van Bambeke F, Tulkens PM. Quantitative analysis of gentamicin, azithromycin, telithromycin, ciprofloxacin, moxifloxacin, and oritavancin (LY333328) activities against intracellular Staphylococcus aureus in mouse $\mathrm{J} 774$ macrophages. Antimicrob. Agents Chemother. 47(7), 2283-2292 (2003).

111 Diacon AH, Donald PR, Pym A et al. Randomized pilot trial of eight weeks of bedaquiline (TMC207) treatment for multidrug-resistant tuberculosis: long-term outcome, tolerability, and effect on emergence of drug resistance. Antimicrob. Agents Chemother. 56(6), 3271-3276 (2012).

112 Cholo MC, Boshoff HI, Steel HC et al. Effects of clofazimine on potassium uptake by a Trk-deletion mutant of Mycobacterium tuberculosis. J. Antimicrob. Chemother. 57(1), 79-84 (2006).

113 Costa IMC, Nogueira LS-C. Pioderma gangrenoso e artrite reumatoide: relato de caso. An. Bras. Dermatol. 80, 81-82 (2005). 
114 Bezerra El, Vilar Mj, Da Trindade Neto PB, Sato Ei. Double-blind, randomized, controlled clinical trial of clofazimine compared with chloroquine in patients with systemic lupus erythematosus. Arthritis Rheum. 52(10), 3073-3078 (2005).

115 Liu B, Liu K, Lu Y et al. Systematic evaluation of structure-activity relationships of the riminophenazine class and discovery of a $\mathrm{C} 2$ pyridylamino series for the treatment of multidrug-resistant tuberculosis. Molecules 17(4), 4545-4559 (2012).

116 Pattyn SR, Rollier MT, Rollier R, Saerens EJ, Dockx P. A controlled clinical trial of continuous and intermittent rifampicin therapy during an initial three months period in lepromatous leprosy: final analysis. Lepr. Rev. 46(2 Suppl.), 129-139 (1975).

117 US Leprosy Panel. Rifampin therapy of lepromatous leprosy. Am. J. Trop. Med. Hyg. 24(3), 475-484 (1975).

118 US Leprosy Panel. Spaced clofazimine therapy of lepromatous leprosy. Am. J. Trop. Med. Hyg. 25(3), 437-444 (1976).

119 Yawalkar SJ, Mcdougall AC, Languillon J et al. Once-monthly rifampicin plus daily dapsone in initial treatment of lepromatous leprosy. Lancet 1(8283), 1199-1202 (1982).

120 Reyes-Javier PD, Tantiongco PR. Chemotherapy trial with a triple-drug regimen, including once-monthly Rimactane (Rifampicin), in patients with multibacillary types of leprosy. Acta Leprol. 1(3), 133-141 (1983).

121 Pattyn SR, Bourland J, Grillone S, Groenen G, Ghys P. Combined regimens of one year duration in the treatment of multibacillary leprosy - I. Combined regimens with rifampicin administered during one year. Lepr. Rev. 60 (2), 109-117 (1989).

122 Pattyn SR, Groenen G, Janssens L, Deverchin J, Ghys P. Combined regimens of one year duration in the treatment of multibacillary leprosy - II. Combined regimens with rifampicin administered during 6 months. Lepr. Rev. 60 (2), 118-123 (1989).

123 Cellona RV, Fajardo TT Jr, Kim Di et al. Joint chemotherapy trials in lepromatous leprosy conducted in Thailand, the Philippines, and Korea. Int. J. Lepr. Other Mycobact. Dis. 58(1), 1-11 (1990).

124 Thomas A, Balakrishnan A, Nagarajan M et al. Controlled clinical trial of two multidrug regimens with and without rifampin in highly bacilliferous BL/LL south Indian patients: a five-year report. Int. J. Lepr. Other Mycobact. Dis. 58(2), 273-280 (1990).

125 Jadhav VH, Patki AH, Mehta JM. Comparison of two multidrug regimens in multibacillary leprosy. Indian J. Lepr. 64(4), 501-504 (1992).

126 WHO. Response to treatment by multidrug regimens in the THELEP controlled clinical drug trials. Subcommittee on Clinical Trials of the Chemotherapy of Leprosy (THELEP) Scientific Working Group of the UNDP/ World Bank/WHO Special Programme for Research and Training in Tropical Diseases. Lepr. Rev. 67(4), 260-279 (1996).

127 Shen J, Bathyala N, Kroeger A et al. Bacteriological results and leprosy reactions among MB leprosy patients treated with uniform multidrug therapy in China. Lepr. Rev. 83(2), 164-171 (2012).

128 Grosset JH, Ji BH, Guelpa-Lauras CC, Perani EG, N'Deli LN. Clinical trial of pefloxacin and ofloxacin in the treatment of lepromatous leprosy. Int. J. Lepr. Other Mycobact. Dis. 58(2), 281-295 (1990).

129 Chan GP, Garcia-Ignacio BY, Chavez VE et al. Clinical trial of sparfloxacin for lepromatous leprosy. Antimicrob. Agents Chemother. 38(1), 61-65 (1994).

130 Ji B, Jamet P, Perani EG, Bobin P, Grosset JH. Powerful bactericidal activities of clarithromycin and minocycline against
Mycobacterium leprae in lepromatous leprosy. J. Infect. Dis. 168(1), 188-190 (1993).

131 Ji B, Jamet P, Perani EG et al. Bactericidal activity of single dose of clarithromycin plus minocycline, with or without ofloxacin, against Mycobacterium leprae in patients. Antimicrob Agents Chemother. 40(9), 2137-2141 (1996).

132 Single-lesion Multicentre Trial Group. Efficacy of single dose multidrug therapy for the treatment of single-lesion paucibacillary leprosy. Indian J. Lepr. 69(2), 121-129 (1997).

133 Ura S, Diório SM, Carreira BG et al. Estudo terapêutico comparando a associação de rifampicina, ofloxacina e minociclina com a associação rifampicina, clofazimina e dapsona em pacientes com hanseníase multibacilar. Hansen. Int. 32(1), 57-65 (2007).

134 Cunha MDG, Virmond M, Schettini AP et al. OFLOXACIN multicentre trial in $\mathrm{MB}$ leprosy FUAM-Manaus and ILSL-Bauru, Brazil. Lepr. Rev. 83(3), 261-268 (2012).

\section{- Websites}

201 WHO: International Clinical Trials Registry Platform.

www.apps.who.int/trialsearch/default.aspx

202 US FDA: Ketek (telithromycin) label (2010). www.accessdata.fda.gov/drugsatfda_docs/ label/2010/021144s013lbl.pdf

203 US FDA: New Molecular Entity Approvals for 2012.

www.fda.gov/Drugs/

Development ApprovalProcess/

DrugInnovation/ucm336115.htm

204 Novartis: Q\&A about the Novartis MDT leprosy donation (2012).

www.novartisfoundation.org/page/content/ index.asp? MenuID =364\&ID = 1010\&Menu= $3 \&$ Item $=43.2 .4$ 